\title{
Nitrogen isotope ratios identify nitrate contamination sources
}

\author{
Dennis E. Rolston $\square$ Graham E. Fogg $\square$ David L. Decker $\square \quad$ Dianne T. Louie $\square \quad$ Mark E. Grismer
}

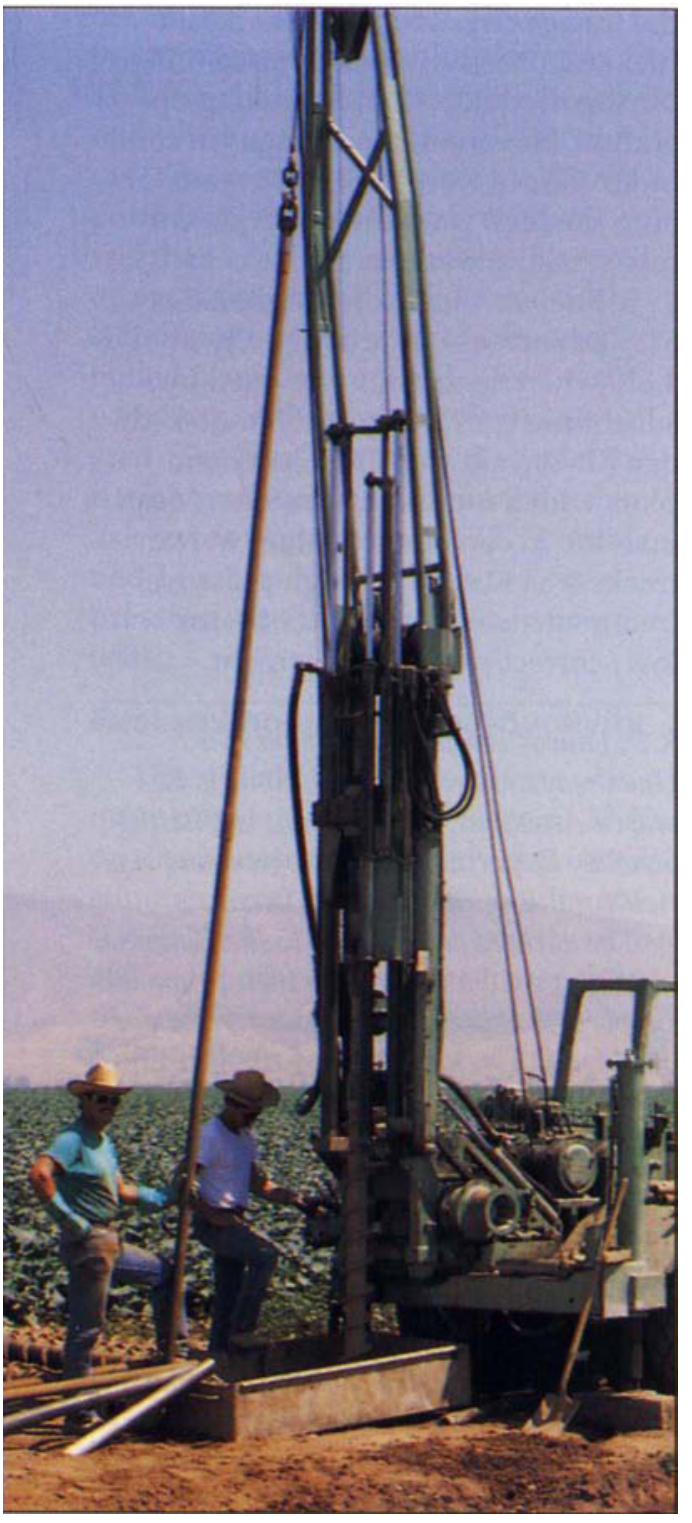

Soll samples were obtalned by drilling 10 feet below the water-table surface.
Nitrate contamination of groundwater is becoming a widespread problem in California. To evaluate the utility of stable nitrogen isotopes for identifying sources of nitrate contamination, nitrogen isotope ratios $\left(\delta^{15} \mathrm{~N}\right)$ were measured on nitrate extracted from core samples taken below natural, fertilizer, on-site sewage disposal (septic) and animal sources in the Sacramento and Salinas valleys. The mean $\delta^{15} \mathrm{~N}$ value from natural sources was not significantly different from that of fertilizer sources. The mean $\delta^{15} \mathrm{~N}$ value from animal sources was significantly different from that of septic sources and natural and/or fertilizer sources. Nitrogen isotope ratios tend to be site specific and should be measured below suspected sources in the subsurface and in groundwater.

Nitrate $\left(\mathrm{NO}_{3}\right)$ concentrations higher than the drinking water standard in groundwater are common in many parts of the world. Multiple sources of $\mathrm{NO}_{3}$ contamination generally occur within the same watershed or groundwater basin. Sources include animal feedlots, horse corrals, dairy waste lagoons, manure applied to land, municipal sewage effluent, on-site sewage disposal systems, urban and agricultural fertilizer, natural soil organic matter and, in some cases, geologic sources. It is often difficult to ascertain which of these sources in a watershed may be contributing significant amounts of $\mathrm{NO}_{3}$ to groundwater.

The nitrogen $(\mathrm{N})$ isotope method of distinguishing sources is based on measuring the two stable isotopes of $\mathrm{N}$ $\left({ }^{14} \mathrm{~N}\right.$ and $\left.{ }^{15} \mathrm{~N}\right)$ in $\mathrm{NO}_{3}$ of the sample. $\mathrm{A}$ common way of representing these ratios is delta ${ }^{15} \mathrm{~N}\left(\delta^{15} \mathrm{~N}\right)$, which is the difference between the ratio $15 \mathrm{~N} / 14 \mathrm{~N}$ of a sample and that of a standard (in the atmosphere) divided by the ratio of the standard, with the entire quantity multiplied by 1,000 . This results in a $\delta{ }^{15} \mathrm{~N}$ value that typically varies less than several per mil $(\%)$ from that of the standard. The percentage of the two isotopes is nearly constant in the atmosphere at $0.366 \% 15 \mathrm{~N}$. However, because of the slight difference in atomic mass of the two isotopes, certain chemical and physical processes often preferentially utilize one isotope, causing a relative enrichment of that isotope in the product and a relative enrichment of the other isotope in the remaining reactants. Because of these isotopic fractionation processes, $\mathrm{NO}_{3}$ from various $\mathrm{N}$ sources has been shown to have different $\mathrm{N}$ isotope ratios. This ratio in a sample depends on the series of reactions that formed the $\mathrm{N}$ compound and the composition of its precursors. If the sample is enriched in $15 \mathrm{~N}$ relative to the standard, then the $\delta^{15} \mathrm{~N}$ value is positive, and if the sample is depleted in ${ }^{15} \mathrm{~N}$, then the $\delta 15 \mathrm{~N}$ value is negative. From literature sources, the $\delta^{15} \mathrm{~N}$ values of $\mathrm{NO}_{3}$ from soil organic nitrogen, fertilizer, animal waste and septic tank effluent range from approximately +2 to $+8 \%,-3$ to 
$+2 \%$, +9 to $+25 \%$ and +6 to $+25 \%$, respectively.

This study evaluates the use of $\mathrm{N}$ isotope ratios as a tool for identifying $\mathrm{NO}_{3}$ contamination sources in groundwater for certain California conditions. The $\delta^{15} \mathrm{~N}$ values in soil water and groundwater were measured in vertical profiles directly beneath various sources of $\mathrm{NO}_{3}$ contamination (for example, fertilized fields, animal waste sites, septic systems and unfertilized, uncultivated land), from the source to the groundwater.

\section{Sampling in Davis, Salinas Valley}

Two study areas were chosen for field sampling, based on differing hydrogeologic conditions and ease of access for drilling. These areas were in the southern Sacramento Valley, where all sampling was performed in the vicinity of Davis, and in the Salinas Valley. Each study region contained sampling sites representing four different sources of $\mathrm{NO}_{3}$ : natural soil organic matter, inorganic fertilizer, animal feedlot/dairy and septic tank effluent. Soil and subsurface sampling was accomplished by drilling and sampling with an 8-inch-diameter, continuous-flight, hollow-stem auger and with a 2.5-inch-diameter California split spoon sampling ahead of the auger. Cores were taken continuously from the ground surface to the water table. Drilling continued into the water table to a depth of 10 feet below the water-table surface whenever possible. A water sample was collected from the bottom of each borehole upon reaching groundwater, using a bailer inside the auger. Subsamples of the core were taken approximately every 5 feet and were preserved for analysis. After the core was taken in the field, the sample was placed in a polyethylene zip-lock bag and placed in an ice chest filled with dry ice. The sample was then transferred to a freezer until it was processed.

\section{Nitrogen isotope analyses}

Nitrate in the soil samples was extracted with deionized water (1:5). Samples that were still cloudy after vacuum filtering were centrifuged and the decantant refiltered. A small amount of the thawed soil was taken to determine moisture content.

Steam distillation was used to convert the inorganic forms of $N$ in the soil-water extracts to a stable form of ammonium salt needed for $\mathrm{N}$ isotope analysis. These samples were then sent to a laboratory for $\mathrm{N}$ isotope analysis. Standard deviation of 6 to 12 samples of reference standards was no larger than $0.8 \delta^{15} \mathrm{~N}$ units. Multiple extractions of field samples were generally within this same range. Thus we do not consider samples significantly different if they fall within $\pm 1 \delta^{15} \mathrm{~N}$ unit.

\section{$\mathrm{NO}_{3}$ varies with location, depth}

We drilled 26 boreholes during this study. Results are shown in terms of $\mathrm{NO}_{3}$ concentrations and $\delta 15 \mathrm{~N}$ values versus depth for the Davis area (figs. 1 and 2) and the Salinas Valley area (figs. 3 and 4). Some gaps occur in the $\delta 15 \mathrm{~N}$ values due to insufficient $\mathrm{NO}_{3}$ to conduct isotope analysis. Concentrations of ammonium, chloride and sulfate were also determined and used in the interpretation, but are not plotted here. In general, ammonium concentrations were negligibly small.

$\mathrm{NO}_{3}$ concentrations vary considerably with location and depth owing to differing land uses, soil-water fluxes and geochemical processes (figs. 1 and 3). Most of the data represent nitrate in soil-water extracts expressed as $\mu \mathrm{g} / \mathrm{g}$ oven-dried soil.

As expected, $\mathrm{NO}_{3}$ concentrations beneath the natural sources were low. $\mathrm{NO}_{3}$ concentrations beneath the septic sources also tended to be low. This could be caused by the boreholes not intercepting the main discharge zones of the on-site sewage effluent, which can seep from the leach lines or pits in a spatially and temporally erratic fashion. Nevertheless, we are confident that our sampling captured enough $\mathrm{NO}_{3}$ to register $\delta 15 \mathrm{~N}$ signatures of the various sources. The high $\mathrm{NO}_{3}$ concentrations in shallow groundwater beneath the fertilizer, feedlot and septic sites in the Davis area and beneath the fertilizer and feedlot sites in the Sali-

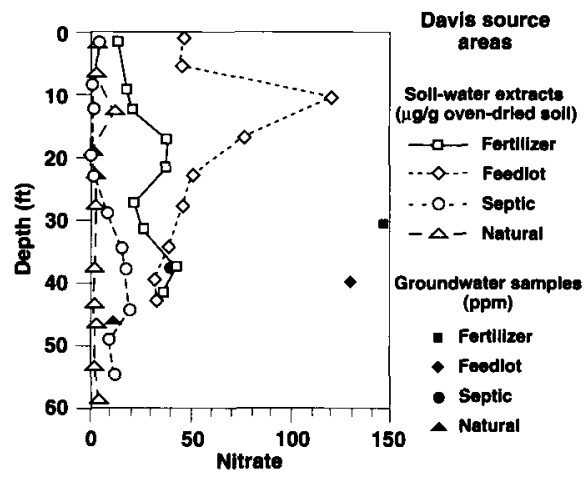

Fig. 1. $\mathrm{NO}_{3}$ concentrations with depth for inorganic fertilizer, animal feedlot, septlc tank (on-site sewage dlsposal) and natural soll organic matter sites In the Davis area (southern Sacramento Valley). Solld symbols represent bailed groundwater samples. Soll-water extract concentrations are In $\mu \mathrm{g} / \mathrm{g}$ oven-dried soll, and groundwater concentrations are In ppm.

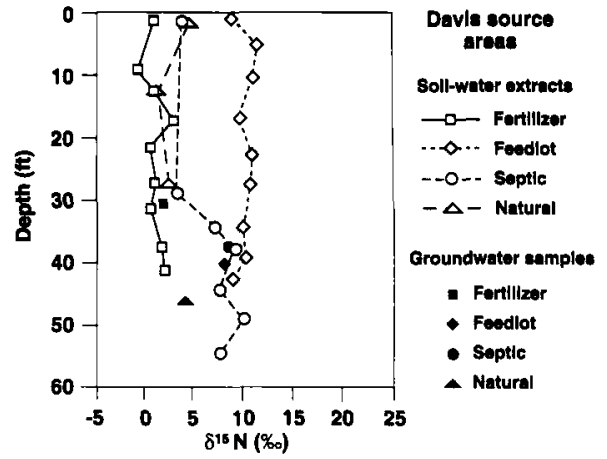

Fig. 2. $\delta^{15} \mathrm{~N}$ concentrations with depth for inorganic fertllizer, animal feedlot, septic tank (on-site sewage disposal) and natural soil organic matter sites in the Davis area (southern Sacramento Valley). Solid symbols represent bailed groundwater samples.

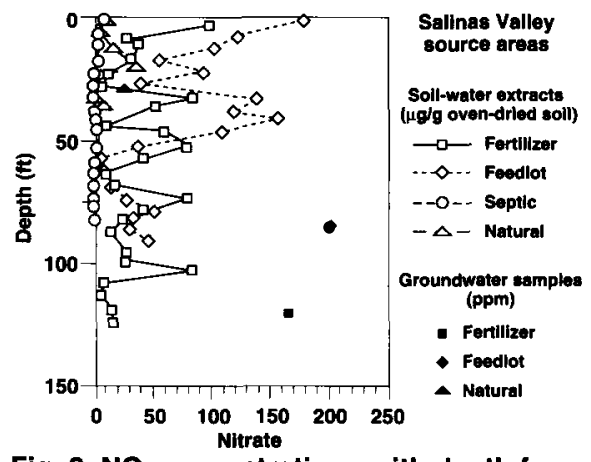

Fig. 3. $\mathrm{NO}_{3}$ concentrations with depth for inorganic fertilizer, animal feedlot, septic tank (on-site sewage disposal) and natural soil organic matter sites in the Sallnas Valley. Solid symbols represent bailed groundwater samples. Soil-water extract concentrations are in $\mu \mathrm{g} / \mathrm{g}$ oven-dried soil, and groundwater concentrations are in ppm. 




Fig. 4. $\delta^{15} \mathrm{~N}$ concentrations with depth for inorganic fertilizer, animal feedlot, septic tank (on-site sewage disposal) and natural soil organic matter sites in the Salinas Valley. Solid symbols represent bailed groundwater samples.

nas Valley could reflect both local and off-site sources.

\section{Natural soil organic matter}

sources. ${ }^{15} \mathrm{~N}$ values beneath the unfertilized, natural soil organic matter sites were very consistent among the borings in the unsaturated zone and varied between about zero and $+5 \%$ (figs. 2 and 4). The $\delta^{15} \mathrm{~N}$ values in the groundwater samples for the Salinas site were all too high for a natural organic matter source and suggest a likely non-natural source in the upgradient direction.

\section{On-site sewage disposal}

sources. $\delta^{15} \mathrm{~N}$ values from the Davis on-site sewage disposal (septic) site (fig. 2) showed an increasing trend with depth, but were well below the largest ratios expected for animal waste. This borehole was drilled between two leach lines spaced 25 feet apart. We suspect that water from the leach lines did not move far enough horizontally to intersect the borehole location until a substantial depth was reached; this would explain the low concentrations of $\mathrm{NO}_{3}$ and low $\delta^{15} \mathrm{~N}$ values in the shallow section. At the Salinas site (fig. 4), the borehole was drilled beside a deep vertical sewage disposal pit. Except for one very high $\delta^{15} \mathrm{~N}$ value at the Salinas site, most of the $\delta^{15} \mathrm{~N}$ values from the human waste disposal systems lie between +5 and $+10 \%$.

Animal waste sources. At the Davis animal waste site, a horse corral that had been in use for at least 30 years, the $\delta 15 \mathrm{~N}$ value was consistent at about $+10 \%$ throughout the vertical subsurface profile (fig. 2). The groundwater sample showed a slightly lower $\delta 15 \mathrm{~N}$ value than the soil water. At the Salinas Valley animal waste site, three boreholes were drilled in two of four abandoned dairy waste evaporation ponds and the animal feeding pens. The borehole with the most consistent $\delta^{15} \mathrm{~N}$ values of the three boreholes had a nearly constant value of about $+17 \%$ in the upper 50 feet of the profile (fig. 4). Below 50 feet, the $\delta 15 \mathrm{~N}$ values decreased to around $+6 \%$; however, the other two boreholes at this site showed high $\delta^{15} \mathrm{~N}$ values both deep and shallow. The spatial variability of $\delta^{15} \mathrm{~N}$ values at this site can be attributed to subsurface heterogeneity and to the fact that the site contains several point sources of animal waste.

Fertilizer sources. Five boreholes were drilled at the Davis site and 10 at the Salinas site. Figures 2 and 4 give examples of $\delta^{15} \mathrm{~N}$ values with depth for the two sites. The Davis site has been cropped with corn, alfalfa and sugar beets for many years. The Salinas site is in an irrigated agricultural field that has been in a mixed vegetable cropping system for several decades. Although most of the fertilizer applied was inorganic $\mathrm{N}$, some compost containing animal waste was also applied occasionally at the Salinas site. The $\delta^{15} \mathrm{~N}$ values for these sites were nearly constant with depth, consistent with the long-term use of fertilizer. The constant $\delta^{15} \mathrm{~N}$ values with depth also indicate that denitrification in the subsurface must have been small. The cyclic high-low trend in $\mathrm{NO}_{3}$ concentrations beneath the Salinas site (fig. 3 ) is due to geologic layering of the subsurface profile at this location, with the lower values tending to locate in the coarser-grained sediments. The lack of similar cyclicity in $\delta^{15} \mathrm{~N}$ at the same borehole (fig. 4) attests to the independence of $\delta^{15} \mathrm{~N}$ values with respect to concentration.

\section{Comparisons of different}

sources. Table 1 shows statistical comparisons of the differences in mean $\delta^{15} \mathrm{~N}$ values for the various source types and locations. These sta- tistics are based on all of the $\delta^{15} \mathrm{~N}$ data, including those boreholes not shown in figures 1 through 4 . The mean $\delta^{15} \mathrm{~N}$ value for the agricultural (fertilizer) source was not significantly different from the mean of the natural background source at the $95 \%$ confidence level. The animal sources were significantly different from the septic sources and the fertilizer and natural sources.

In addition, we made statistical comparisons between mean $\delta 15 \mathrm{~N}$ values between areas for each source type. There was no significant difference in means for the natural, septic and animal waste sources between the Davis and Salinas areas, but means for the fertilizer sites were significantly different. The elevation of mean $\delta^{15} \mathrm{~N}$ values at the Salinas fertilizer site over those at the Davis fertilizer site may be partly due to the occasional application of compost containing animal waste at the Salinas location and/or to a significant amount of nitrogen-fixing legumes in the cropping history of the Davis location.

\section{Mixed sources of groundwater $\mathbf{N}$}

The $\delta^{15} \mathrm{~N}$ data shown in figures 2 and 4 are chiefly from the unsaturated zone directly beneath known source types. In groundwater investigations of $\mathrm{NO}_{3}$ contamination, however, much of the $\delta^{15} \mathrm{~N}$ data will represent deeper groundwater pumped from production wells. If this deeper groundwater contains $\mathrm{NO}_{3}$ contamination from more than one source, the $\delta^{15} \mathrm{~N}$ values will reflect a mixture of those sources. Therefore it is typically not possible to "fingerprint" the source of $\mathrm{NO}_{3}$ contamination by merely measuring $\delta^{15} \mathrm{~N}$ in a few water wells. Clearly, determining the sources of $\mathrm{NO}_{3}$ contamination in groundwater commonly requires careful hydrogeologic analysis of groundwater migration rates and flow paths as well as an exhaustive inventory of potential $\mathrm{NO}_{3}$ sources. In this analysis, the $\delta^{15} \mathrm{~N}$ technique is an important tool rather than "the solution."

Even if an area contains only one source of $\mathrm{NO}_{3}$ contamination that is theoretically distinguishable by $\delta^{15} \mathrm{~N}$ 
techniques, it is possible that the $\delta^{15} \mathrm{~N}$ values measured in groundwater or deep unsaturated zone will be measurably higher than in the shallow zone directly beneath the source. The reason is that denitrification, the process whereby $\mathrm{NO}_{3}$ is converted to $\mathrm{N}_{2} \mathrm{O}$ and $\mathrm{N}_{2}$ gases, can raise the $\delta^{15} \mathrm{~N}$ values above those of the original source. Denitrification is most likely when anaerobic conditions occur in a biologically active soil zone, which in turn most likely appears when the water table is within a few feet of land surface. When the water table is shallow, there is greater likelihood that anaerobic conditions of the saturated zone extend sufficiently into the biologically active soil zone to drive denitrification. Clearly, in addition to hydrogeologic analysis, application of the $\delta^{15} \mathrm{~N}$ technique requires collecting data on $\delta^{15} \mathrm{~N}$ values beneath the sources of concern to detect whether denitrification is occurring and to verify the $\delta^{15} \mathrm{~N}$ signatures of the sources. Additional measurement of $\delta^{15} \mathrm{~N}$ values beneath septic sources is particularly needed because of the dearth of such data in the literature.

In this study, little to no evidence of denitrification was found, presumably because the water table was 40 to more than 100 feet below land surface at all sites, well below the soil zone. That is, $\delta^{15} \mathrm{~N}$ values tended not to increase with depth, except beneath the Davis septic site (fig. 2) and in one of the boreholes drilled at the Salinas septic site. At the Davis septic site, the borehole did not intersect the plume until a depth of approximately 25 feet, which explains the increase in $\delta^{15} \mathrm{~N}$ value with depth. At the Salinas Valley septic tank site, the $\delta^{15} \mathrm{~N}$ value increased with depth and the $\mathrm{NO}_{3}$ concentrations decreased with depth, which could be indicative of denitrification. In addition, a few locally elevated $\delta^{15} \mathrm{~N}$ values were found at various sites, such as the deepest sample beneath the Salinas Valley fertilizer site (fig. 4). However, $\delta{ }^{15} \mathrm{~N}$ values from the other boreholes and from deeper groundwater verify that these elevated values are isolated anomalies, apparently caused by highly localized processes.

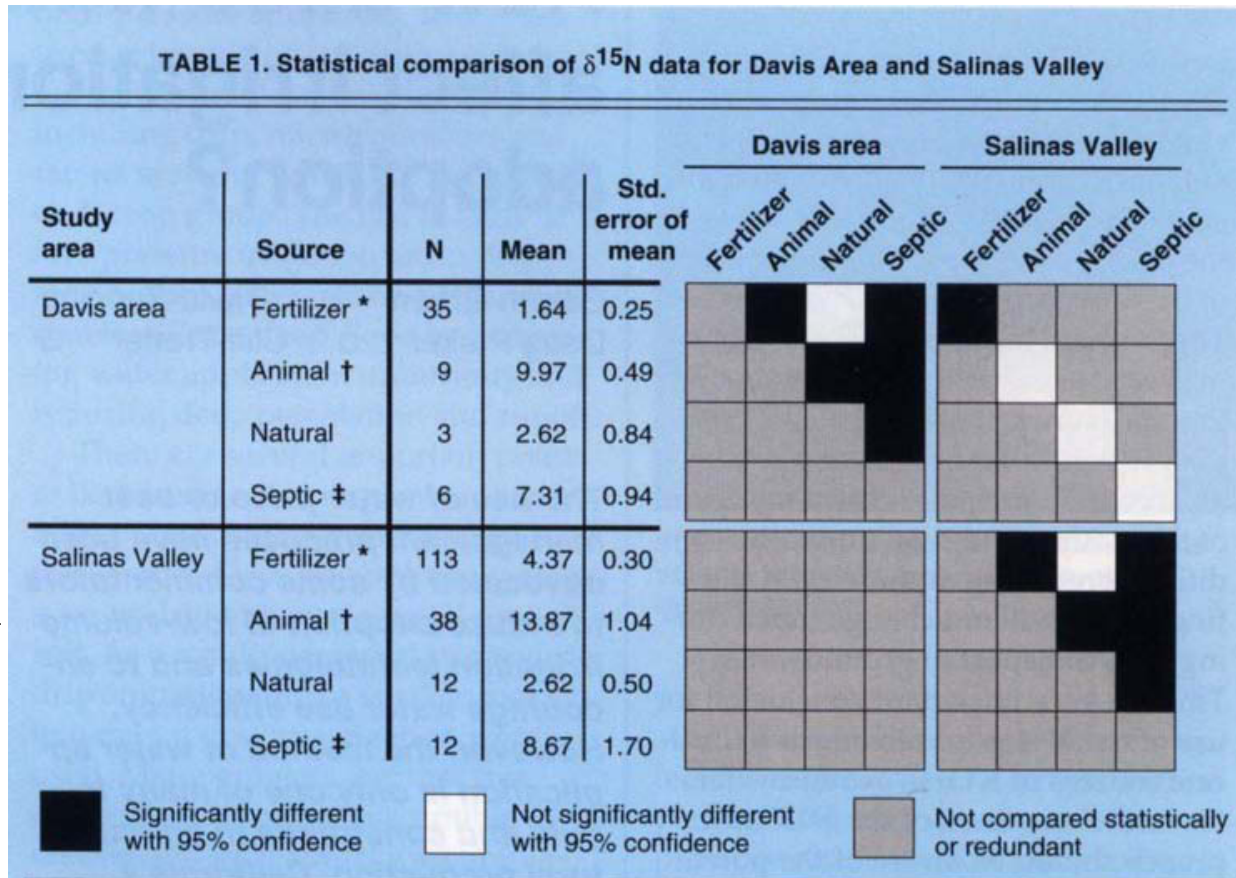

Note: The Tukey-Kramer HSD (honestly significant difference) test was used to analyze statistical significance of means of all sources from a given study area simultaneously (for example, all sources from the Davis area). The Student's $t$ test was used to compare means for the same source but from two different study areas (for example, fertilizer source in Davis area and Salinas Valley). To see the results of the statistical significance test between source sites in Davis and Salinas, find, for example, "Davis area animal" in the left-hand columns and read the outcome (blank = not significantly different) in the column labeled "Salinas Valley animal" to the right.

"Inorganic fertilizer. Fertilizer treatments at the Salinas Valley site also included some compost that contained animal waste.

t Horse corral in Davis; feedlot in Salinas Valley.

‡On-site sewage disposal systems (one system in Davis area and one in Salinas Valley). $\delta^{15} \mathrm{~N}$ values beneath and near septic tank leach fields were highly variable due to geometric complexity of the septic effluent plumes and, at the Salinas site, due to localized denitrification.

\section{Isotope ratios as indicators}

Nitrogen in the subsurface zone existed primarily as nitrate, except for one septic and one dairy lagoon site in the Salinas Valley where significant amounts of ammonium existed. The $\delta^{15} \mathrm{~N}$ values determined from the various sites fall within the range of values reported in the literature, but with lower variances. The mean $\delta^{15} \mathrm{~N}$ value for the natural background sites was about $+2.6 \%$ in both the Salinas Valley and Davis study areas. Mean $\delta^{15} \mathrm{~N}$ value for the fertilized sites was slightly greater than for the natural sites with $+4.4 \%$ in the Salinas Valley and slightly lower at $+1.6 \%$ in the Davis area. The animal waste sites had a mean value of $+10 \%$ at Davis and $+14 \%$ in Salinas Valley. The on-site sewage disposal sites had mean $\delta^{15} \mathrm{~N}$ values of about $+7.3 \%$ at Davis and $+8.7 \%$ at Salinas Valley. It is clear from our data that the $\delta^{15} \mathrm{~N}$ methodology cannot be used to distinguish between fertilizer and natural soil organic matter sources. However, in the sites that we examined, the $\delta^{15} \mathrm{~N}$ method can be used to distinguish between animal sources and fertilizer and/or soil organic matter sources. In addition, our data show that there is a significant difference between mean $\delta^{15} \mathrm{~N}$ of the animal and septic sources. These results exemplify the necessity of measuring the specific $\delta^{15} \mathrm{~N}$ of suspected sources of $\mathrm{NO}_{3}$ contamination for the particular area of interest. Simply using values from the literature may not allow clear separation of source types. 
The $\delta 15 \mathrm{~N}$ values at most sites were fairly consistent with depth from the surface to the water table. There is no evidence from our data that denitrification is a significant process at any of the sites, with the possible exception of the Salinas Valley septic tank site. Thus, except for one site in the eight main test sites, the results demonstrate that measuring the $\delta^{15} \mathrm{~N}$ value immediately below the $\mathrm{NO}_{3}$ source can be an accurate indicator of the fingerprint of that source and that, under the conditions prevailing at these sites, the fingerprint will not change much during $\mathrm{NO}_{3}$ transport to groundwater. This is a very important conclusion for use of the $\mathrm{N}$ isotope technique to indicate sources of $\mathrm{NO}_{3}$ in groundwater. Nevertheless, users of the $\delta 15 \mathrm{~N}$ approach should be aware of the potential for mixing of $\delta^{15} \mathrm{~N}$ from multiple sources and of denitrification under some circumstances. Careful hydrogeologic characterization as well as sampling of both the unsaturated and saturated zones beneath potential sources are therefore typically required for successful application of the $\delta 15 \mathrm{~N}$ approach.

\section{D.E. Rolston, G.E. Fogg and M.E.}

Grismer are Professors of Soil Science, Hydrogeology and Hydrologic Science, respectively, and D.T. Louie is Staff Research Associate, Department of Land, Air and Water Resources, UC Davis; and D.L. Decker was postgraduate researcher and is presently graduate student, University of Nevada, Reno.

This research was supported by the California Water Resources Control Board, Interagency Agreement No. 1-155253-0, Monterey County Water Resources Agency and the U.S. Environmental Protection Agency Assistance Agreement Nos. 1009564-91-0 and C9009532-90-1.

The contents do not necessarily reflect the views and policies of the U.S. EPA, Monterey County or the California Water Resources Control Board. The authors appreciate the assistance of Heike Clausnitzer, Amy Wong, Mike Tolin and Brian Lindsay in laboratory analytical work and of Dr. Richard Mulvaney at the University of Illinois for $\delta^{5} \mathrm{~N}$ analysis.

\section{How does water price affect irrigation technology adoption?}

\author{
Gareth Green \\ Doug Parker \\ 口 David Sunding \\ $\square \quad$ Cliff Trotter $\square$
}

The use of water price or best management practices have been advocated by some commentators to induce adoption of low-volume irrigation technologies and to encourage water use efficiency. However, the method of water application Is only one of many inputs and constraints in agricultural production. Callfornia's highly diverse topography, soil types and variety of crops influence irrigation technology choices, therefore a policy mandating adoption of modern technologies is likely to have undesirable impacts. Crop type appears to be a major consideration in technology choice, as some technologies may be incompatible with some types of crops.

Continued urban population growth, heightened public awareness of the environmental benefits of in-stream water flows, and the virtual halt of water supply development in California have increased pressure on state and federal agencies to reallocate water away from agriculture. Many publicinterest groups and policy makers have suggested that growers could increase their use of low-volume irrigation technologies while maintaining current production levels. Some interests have even advocated imposing agricultural "best management practices" mandating the adoption of irrigation technologies. California growers have been criticized for their "irrational" and "inefficient" irrigation technology choices. It has been suggested that growers could maintain or increase their profitability while using

\author{
口 David Zilberman \\ Steve Collup
}

fewer resources. In this article, we assess whether technology choice is consistent with the assumption of profit maximization and, if so, determine which factors most influence technology choice.

Some commentators have advocated the use of water price as a policy tool to induce adoption of low-volume irrigation technologies and to encourage increased water-use efficiency. Specifically, environmentalists and many economists frequently assert that irrigation water should be priced to encourage adoption of modern technologies and reflect the value of water outside agriculture. However, the effectiveness of water price to achieve these goals may be limited because the method of water application is only one of many crucial inputs and constraints in agricultural production.

Our model demonstrates that large increases in the price of water generally encourage heavier reliance on drip and other low-pressure irrigation systems for certain crops, but may have only modest effects on adoption decisions for other modern irrigation technologies.

\section{Irrigation decisions in Arvin}

We selected the Arvin Edison Water Storage District, located in the southern San Joaquin Valley at the terminus of the Friant-Kern Canal, as our study area. There is wide variation in the types of irrigation technologies employed in the District: $25 \%$ furrow or flood, $49 \%$ high-pressure sprinkler and $26 \%$ low-pressure drip and microsprinkler (table 1). This variation makes the District ideal for analysis because there is a large amount of variability, yet the area is relatively 